\title{
Identification of the contact sex pheromone of Gastrophysa atrocyanea (Coleoptera: Chrysomelidae)
}

\author{
Wataru Sugeno, ${ }^{* \dagger}$ Masatoshi Hori and Kazuhiro MATsuda \\ Laboratory of Insect Science and Bioregulation, Graduate School of Agricultural Science, Tohoku University; Sendai 981-8555, \\ Japan
}

(Received 5 September 2005; Accepted 27 December 2005)

\begin{abstract}
The mating behavior of the male Gastrophysa atrocyanea, that is, extrusion of the aedeagus, was elicited by the cuticular hydrocarbons on the surface of the female body. Males attempted to mate with a dummy treated with the female equivalent of the female elytra extracts. After fractionation of the elytra extracts by Florisil column chromatography and reverse phase high performance liquid chromatography, two fractions, consisting mainly of methylheptacosanes and methylnonacosanes were found to elicit the male mating behavior. These compounds, synthetic 9-methylheptacosane, 11-methylheptacosane, 9-methylnonacosane and 11-methylnonacosane, were contained in active fractions and showed high pheromonal activity. Therefore, these monomethylalkanes were considered to be contact sex pheromones of this beetle. However, synthetic 13-methylheptacosane, 13-methylnonacosane and 15-methylnonacosane, positional isomers of active monomethylalkanes, also contained in the active fractions, did not have the activity. A mixture of these seven monomethylalkanes at approximately natural concentrations also had enough activity to elicit the male mating behavior. Furthermore, the results of a bioassay using some related structural monomethylalkanes revealed that the length of the carbon backbone and the position of the methyl branch greatly influenced the pheromonal activity of G. atrocyanea.
\end{abstract}

Key words: Gastrophysa atrocyanea; contact sex pheromone; mating behavior; cuticular hydrocarbon; monomethylalkane

\section{INTRODUCTION}

Cuticular lipids on an insect's body have been known to play important roles in chemical communication. These lipids facilitate sexual behavior (sex pheromones) (e.g., Coleoptera, Dictyoptera, Diptera and Lepidoptera), nestmate recognition (Hymenoptera and Isoptera) and host recognition (Hymenoptera) (Blomquist et al., 1996). In Coleoptera, particularly Cerambycidae, the function of the cuticular hydrocarbons as contact sex pheromones has been extensively investigated, and the chemical structure of these pheromones has been identified in several species (Fukaya et al., 1996, 2000; Ginzel et al., 2003a, b; Zhang et al., 2003). Among the Chrysomelidae, which comprise a large proportion of Coleoptera and many agricultural pests, the existence of a contact sex pheromone has only been reported for the Colorado potato beetle, Leptinotarsa decemlineata: male mating behaviors were elicited by extracts from the whole female body or elytra (Jermy and Butt, 1991; Otto, 1997). In our preliminary observation of mating behavior of some chrysomelid beetles including Gastrophysa atrocyanea, males tapped the female body with the antenna and licked it; these behaviors resembled those of several cerambycid species, the females of which produce a contact sex pheromone. In Chrysomelidae, contact sex pheromones have been indicated to play an important role in mating, however the contact sex pheromone has not been chemically identified for any species.

In this study, we investigated the contact sex pheromone of $G$. atrocyanea. The candidate monomethylalkanes as contact sex pheromones

\footnotetext{
* To whom correspondence should be addressed at: E-mail: sugewtr@yahoo.co.jp

† Present address: Agricultural Experiment Station, Toyama Agricultural Research Center, Yoshioka, Toyama 939-8153, Japan DOI: $10.1303 /$ aez.2006.269
} 
were synthesized and examined for pheromonal activity. In addition, we evaluated the relationship between the pheromonal activity and chemical structure.

\section{MATERIALS AND METHODS}

Insects. Gastrophysa atrocyanea were continually maintained in the laboratory for all life stages on fresh dock, Rumex obtusifolius L. leaves at $25^{\circ} \mathrm{C}$ (16L : 8D photoperiod). The sex was checked after emergence, and the sexes were separately maintained in cages covered with soil. The adults fed on the leaves for about $1 \mathrm{wk}$, and then they burrowed into the soil to diapause. The diapause adults were kept at $25^{\circ} \mathrm{C}$ for $5 \mathrm{mo}$ and subsequently transferred to $5^{\circ} \mathrm{C}$. After spending about $1 \mathrm{mo}$ at $5^{\circ} \mathrm{C}$, the adults crawled out of the soil. The post-diapause males and females were individually reared on fresh leaves in plastic Petri dishes with moist filter paper at $25^{\circ} \mathrm{C}$ (16L : 8D photoperiod). All examinations were carried out on these post-diapause virgin adults.

Extraction. Post-diapause females that had fed on Rumex leaves for 3-4d were killed by freezing at temperatures below $-18^{\circ} \mathrm{C}$. The elytra of the killed females were dissected from the body and extracted with chloroform for $24 \mathrm{~h}$ at $-18^{\circ} \mathrm{C}$. After the elytra were removed and filtrated, the crude extracts were freeze-dried and stored at $-18^{\circ} \mathrm{C}$ until use.

Chromatography. The crude extracts dissolved with a small volume of chloroform were chromatographed on a column of Florisil (containing 10\% water, 60-100 mesh, Wako Pure Chemical Industries Ltd.) and eluted with hexane. The hexane fraction was further fractionated with reversephase high performance liquid chromatography (YMC-Pack ODS-AM, 120A, 250×4.6 mm ID, YMC Co., Ltd.) elute with $25 \%$ ethyl acetate in methanol at a flow rate of $1.0 \mathrm{ml} / \mathrm{min}$, and at $30^{\circ} \mathrm{C}$ using a column oven. Peaks were monitored using an IR detector. Fractions were collected as follows: fraction $1 ; 0-18 \mathrm{~min}$, fraction $2 ; 18-26 \mathrm{~min}$, fraction $3 ; 26-32 \mathrm{~min}$, fraction $4 ; 32-38 \mathrm{~min}$, fraction $5 ; 38-55 \mathrm{~min}$. These fractions were freeze-dried and stored at $-18^{\circ} \mathrm{C}$ until use.

Chemical analysis. Gas chromatography was conducted on DB-5 $(30 \mathrm{~m} \times 0.25 \mathrm{~mm} \quad$ (ID) $\times$ $0.25 \mu \mathrm{m}$ film thickness, $\mathrm{J} \& \mathrm{~W}$ Scientific) with a
Hitachi G-5000A gas chromatograph equipped with a flame ionization detector (FID). The injector and detector temperature were $320^{\circ} \mathrm{C}$. The temperature program of the column oven was $50-230^{\circ} \mathrm{C}$ at $30^{\circ} \mathrm{C} / \mathrm{min}, 230-300^{\circ} \mathrm{C}$ at $2^{\circ} \mathrm{C} / \mathrm{min}$ and $300^{\circ} \mathrm{C}$ for $20 \mathrm{~min}$. Helium was used as the carrier gas at a column head pressure of $100 \mathrm{kPa}$ and the split ratio was about $1: 20$.

Gas chromatography-mass spectrometry was conducted with a Hewlett-Packard 6890 series gas chromatograph with HP-5 $(30 \mathrm{~m} \times 0.32 \mathrm{~mm}$ (ID) $\times$ $0.25 \mu \mathrm{m}$ film thickness, Hewlett-Packard) interfaced to a JEOL JMS-700 mass spectrometer (EI mode, $70 \mathrm{eV}$, chamber temperature $150^{\circ} \mathrm{C}$ ). The injector temperature was $280^{\circ} \mathrm{C}$. The temperature program of the column oven was $50-230^{\circ} \mathrm{C}$ at $30^{\circ} \mathrm{C} / \mathrm{min}, 230-320^{\circ} \mathrm{C}$ at $2^{\circ} \mathrm{C} / \mathrm{min}$ and $320^{\circ} \mathrm{C}$ for $30 \mathrm{~min}$.

The peaks were identified by their Kovats retention indices (RI) (Kovats, 1965) and their characteristic fragmentation patterns in GC-MS analysis (Jackson and Blomquist, 1976; Pomonis et al., 1978, 1980; Carlson et al., 1998). The identification of $n$-alkanes was confirmed by co-injections of authentic compounds. The methylheptacosanes and methylnonacosanes were also confirmed by comparison of their retention times and characteristic fragmentation patterns of mass spectra with the synthetic compounds. The quantitative data for each compound were estimated by comparison of the peak area with a calculation curve of $n$-alkane having the same length carbon backbone.

Synthesis of monomethylalkanes. 9-Methylheptacosane $\left(9-\mathrm{MeC}_{27}\right)$ was synthesized from 1bromooctadecane and 2-decanone by Grignard reaction, subsequent dehydration and hydrogenation reaction. Other monomethylalkanes were synthesized by the same process as $9-\mathrm{MeC}_{27}$ but were started from proper 1-bromoalkanes and 2-ketones, respectively. These synthetic monomethylalkanes were purified by HPLC when necessary.

The Kovats retention indices and the characteristic ions of the synthetic monomethylalkanes were as follows: $7-\mathrm{MeC}_{23}$; $\mathrm{RI}=2341,112 / 113,252 / 253$, $323,338,9-\mathrm{MeC}_{23}$; RI $=2336,140 / 141,224 / 225$, $323 ， 338 ， 5-\mathrm{MeC}_{25} ; \mathrm{RI}=2550,84 / 85 ， 308 / 309$, $351,366,7-\mathrm{MeC}_{25}$; RI $=2541,112 / 113,280 / 281$, $351,366,9-\mathrm{MeC}_{25}$; RI $=2536,140 / 141,252 / 253$, $351,366,11-\mathrm{MeC}_{25}$; RI $=2534,168 / 169,224 / 225$, $351,366,8-\mathrm{MeC}_{26}$; RI $=2638,126 / 127,280 / 281$, 
365, 380, 7- $\mathrm{MeC}_{27} ; \mathrm{RI}=2741,112 / 113,308 / 309$, $379,394,9-\mathrm{MeC}_{27} ; \mathrm{RI}=2735,140 / 141,280 / 281$, $379,394,11-\mathrm{MeC}_{27} ; \mathrm{RI}=2733,168 / 169,252 / 253$, $379,394,13-\mathrm{MeC}_{27} ; \mathrm{RI}=2732,196 / 197,224 / 225$, 379, 394, 9- $\mathrm{MeC}_{29}$; RI=2936, 140/141, 308/309, 407, 422, 11- $\mathrm{MeC}_{29}$; RI=2933, 168/169, 280/281, 407, 422, 13- $\mathrm{MeC}_{29}$; RI=2931, 196/197, 252/253, 407, 422, 15- $\mathrm{MeC}_{29}$; RI $=2931,224 / 225,407,422$, $11-\mathrm{MeC}_{31}$; RI=3133, 168/169, 308/309, 435, 450.

Bioassay. The post-diapause males that had fed on Rumex leaves for 4-15d were used for the bioassay. A test sample of the proper concentration with solvent $(10 \mu \mathrm{l})$ was applied to the back face of the head of a stainless spatula (head size: $6 \mathrm{~mm}$ (long axis) $\times 4 \mathrm{~mm}$ (short axis), stalk length: $175 \mathrm{~mm}$ ) as the female dummy and air-dried until the solvent evaporated. A male was released on the stalk of the spatula and was allowed to walk toward the head. When a male reached the head of the spatula, his behavior was observed. For each male, this observation was conducted until he extruded his aedeagus into the dummy or for a maximum of five times. Because no male responded to the dummy to which solvent only was applied $(N=20)$, it was regarded that the male responded to the sample when it extruded aedeagus into the dummy (Fig. 1).

\section{RESULTS}

\section{Isolation of active fractions from female elytra extracts}

When one female equivalent (FE) of the crude extracts was applied to the dummy, $85.2 \%$ of the males attempted to mate with the dummy by extruding their aedeagus (Fig. 1 and Table 1). Following column chromatographic fractionation of the crude extracts on Florisil, $74.1 \%$ of the males responded to the hexane fraction ( $1 \mathrm{FE}$ ) in a manner similar to their response to the crude extracts. This fraction was assumed to contain the contact sex pheromone(s). As the hexane fraction had many compounds (Fig. 2), it was further separated into five fractions by HPLC. Seventy-five and $76.5 \%$ of the males responded to fractions 3 and 4, respectively (each, 1 FE), and there were no significant differences from the responses to the crude extracts and hexane fraction by Holm's sequential Bonferroni test $(p>0.05)$ (Table 1). Thus, fractions 3 and 4 were considered to contain the contact sex

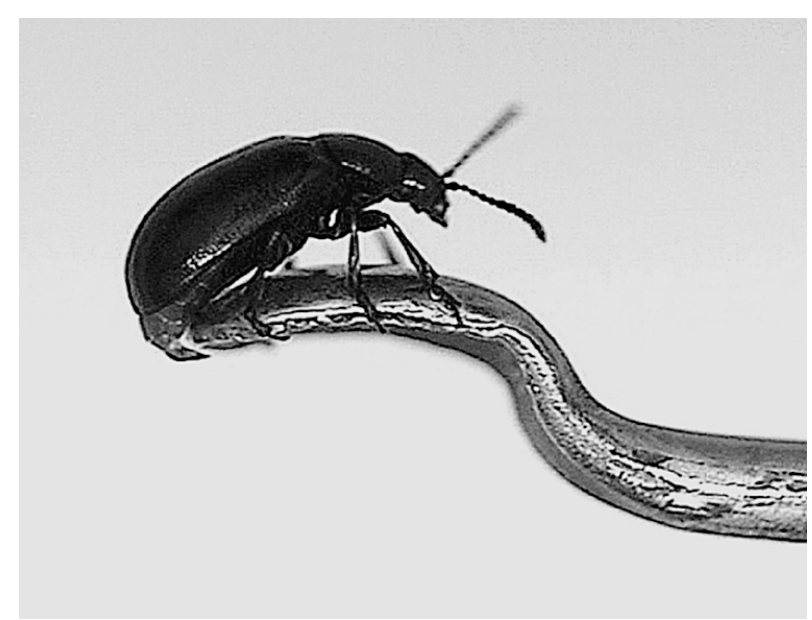

Fig. 1. A male G. atrocyanea extruding aedeagus into the head of a spatula. Female elytra extracts were applied to the back face (it faces the upper side in this figure and maintains this position throughout the bioassay) of the head of spatula.

Table 1. Male responses to female elytra extracts and each fraction

\begin{tabular}{lcc}
\hline \multicolumn{1}{c}{ Treatments $^{\mathrm{a}}$} & $N$ & $\begin{array}{c}\text { Male } \\
\text { responses }(\%)^{\mathrm{b}}\end{array}$ \\
\hline Crude extracts & 54 & $85.2 \mathrm{a}$ \\
Hexane Fr. (Florisil) & 54 & $74.1 \mathrm{a}$ \\
Fr. 1 & 51 & $11.8 \mathrm{~b}$ \\
Fr. 2 & 51 & $35.3 \mathrm{~b}$ \\
Fr. 3 & 52 & $75.0 \mathrm{a}$ \\
Fr. 4 & 51 & $76.5 \mathrm{a}$ \\
Fr. 5 & 52 & $28.8 \mathrm{~b}$ \\
All Fr. & 43 & $72.1 \mathrm{a}$ \\
\hline
\end{tabular}

${ }^{a}$ Each sample was applied to a dummy at $1 \mathrm{FE}$.

${ }^{b}$ Values followed by the same letter indicate no significant differences using Holm's sequential Bonferroni test $(p>0.05)$.

${ }^{c}$ All Fr. means mixture from Fr. 1 to Fr. 5.

pheromone(s), and were analyzed by GC and GCMS.

\section{Identification of components of active fractions}

The GC-FID of the hexane fraction and the peaks for compounds in each fraction separated by HPLC are shown in Fig. 2. The compounds in fractions 3 and 4 detected by the GC-MS analysis are listed in Table 2. In fractions 3 and 4 , some $n$ alkanes, monomethylalkanes and dimethylalkanes were detected; these alkanes accounted for 11, 55 and $34 \%$, respectively, among all of the detected alkanes. In each fraction, methylheptacosanes (9-, 11- 


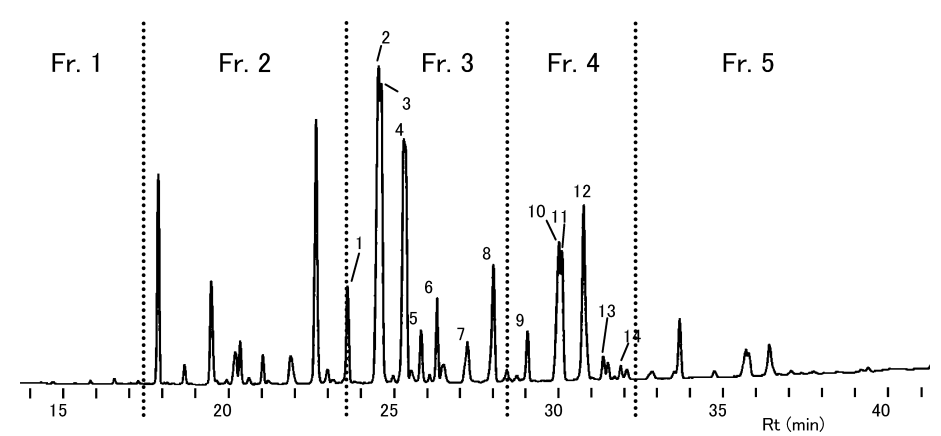

Fig. 2. Gas chromatograph (FID) of the hexane fraction of crude extracts on a Florisil column chromatography. The dotted lines separate the peaks in each HPLC fraction. The numbers of the peaks correspond to the peak number in Table 2. GC condition; column: DB-5 $30 \mathrm{~m} \times 0.25 \mathrm{~mm}$ (ID) $\times 0.25 \mu \mathrm{m}$ film thickness, temperature program: $50-230^{\circ} \mathrm{C}\left(30^{\circ} \mathrm{C} / \mathrm{min}\right), 230-300^{\circ} \mathrm{C}\left(2^{\circ} \mathrm{C} / \mathrm{min}\right)$, $300^{\circ} \mathrm{C}(20 \mathrm{~min})$. See text for further details of GC conditions.

Table 2. Composition of cuticular hydrocarbons of fractions 3 and 4

\begin{tabular}{|c|c|c|c|c|c|}
\hline Fr. No. & Peak No. & Compounds & RI & Characteristic ions & Amount $(\mu \mathrm{g} / \mathrm{FE})^{\mathrm{a}}$ \\
\hline \multirow[t]{10}{*}{3} & 1 & $n$-Heptacosane & 2700 & 380 & 0.12 \\
\hline & 2 & 11-Methylheptacosane & 2735 & $168 / 169,252 / 253,379,394$ & 0.65 \\
\hline & & $\begin{array}{l}\text { 13-Methylheptacosane } \\
(1: 1)^{\mathrm{b}}\end{array}$ & & $196 / 197,224 / 225,379,394$ & \\
\hline & 3 & 9-Methylheptacosane & 2738 & $140 / 141,280 / 281,379,394$ & 0.27 \\
\hline & 4 & 9,13-Dimethylheptacosane & 2764 & $140,295,211,224,393,408$ & 0.59 \\
\hline & & 11,15-Dimethylheptacosane & & $168,267,196,239,393,408$ & \\
\hline & 5 & 5,9-Dimethylheptacosane & 2782 & $85,352,155,281,393,408$ & 0.07 \\
\hline & 6 & $n$-Octacosane & 2800 & 394 & 0.10 \\
\hline & 7 & 10-Methyloctacosane & 2834 & $154 / 155,280 / 281,393,408$ & 0.08 \\
\hline & 8 & 2-Methyloctacosane & 2863 & $365,393,408$ & 0.19 \\
\hline \multirow[t]{9}{*}{4} & 9 & $n$-Nonacosane & 2900 & 408 & 0.07 \\
\hline & 10 & 11-Methylnonacosane & 2934 & $168 / 169,280 / 281,407,422$ & 0.28 \\
\hline & & 13-Methylnonacosane & & $196 / 197,252 / 253,407,422$ & \\
\hline & & $\begin{array}{l}\text { 15-Methylnonacosane } \\
(2: 1: 1)\end{array}$ & & $224 / 225,407,422$ & \\
\hline & 11 & 9-Methylnonacosane & 2937 & $140 / 141,308 / 309,407,422$ & 0.16 \\
\hline & 12 & 11,15-Dimethylnonacosane & 2960 & $168,295,224,239,421,436$ & 0.32 \\
\hline & & 13,17-Dimethylnonacosane & & $196,267,421,436$ & \\
\hline & 13 & 5,9-Dimethylnonacosane & 2981 & $85,379,155,309,421,436$ & 0.04 \\
\hline & 14 & $n$-Triacontane & 3000 & 422 & 0.03 \\
\hline
\end{tabular}

\footnotetext{
${ }^{\text {a }}$ The amount of each compound was estimated by comparing the peak area with the calculation curve of $n$-alkane having the same length carbon backbone.

${ }^{\mathrm{b}}$ Proportion of positional isomers in a single peak was estimated as a comparison of the corresponding fragment ions.
}

and $13-\mathrm{MeC}_{27}$, total $\left.0.92 \mu \mathrm{g} / \mathrm{FE}\right)$ and methylnonacosanes (9-, 11-, $13-$ and $15-\mathrm{MeC}_{29}$, total $0.44 \mu \mathrm{g} / \mathrm{FE})$ were the most abundant.

\section{Pheromonal activity of methylheptacosanes and methylnonacosanes}

Seven major monomethylalkanes in fractions 3 and 4 were synthesized and evaluated for pheromonal activity (Fig. 3). In this bioassay, each alkane was applied to a dummy at a dose of $2.0 \mu \mathrm{g}$, which was considered to be a sufficient amount because the total amount of alkanes detected in fraction 3 was approximately $2.0 \mu \mathrm{g} / \mathrm{FE}$.

In response to the dummies treated with 9$\mathrm{MeC}_{27}, 11-\mathrm{MeC}_{27}, 9-\mathrm{MeC}_{29}$ and $11-\mathrm{MeC}_{29}, 71.7$, $60.1,62.1$ and $78.9 \%$, respectively, of tested males 


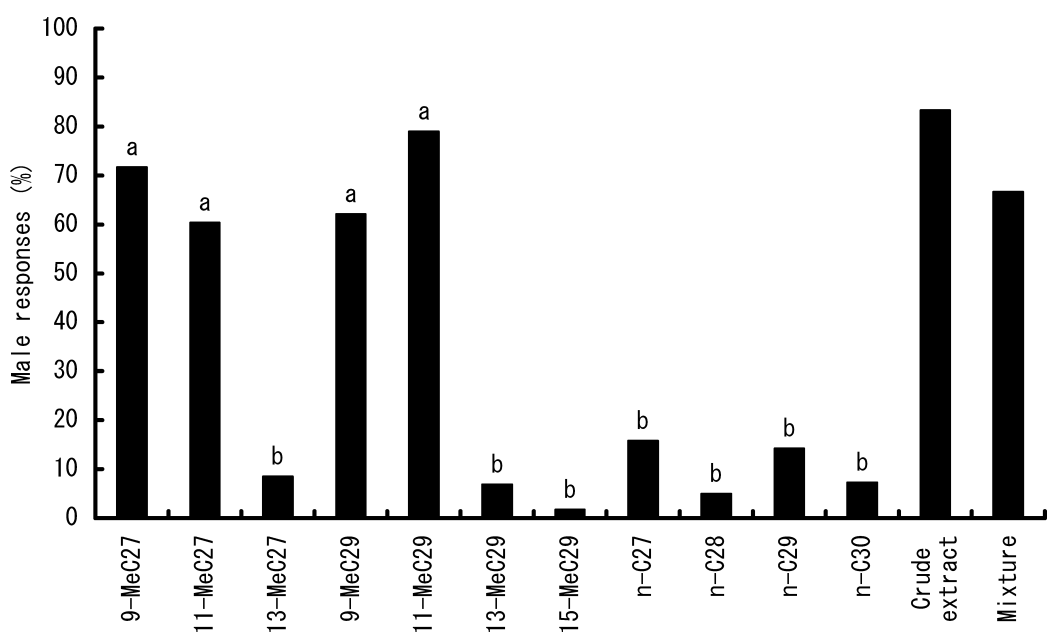

Fig. 3. Male responses to synthetic monomethylalkanes, $n$-alkanes, female crude extract and a mixture of monomethylalkanes. Each alkane was applied to a dummy at $2.0 \mu \mathrm{g}$. Crude extract or mixture was applied to a dummy at $1 \mathrm{FE}$ or $9-\mathrm{MeC}_{27}, 11-\mathrm{MeC}_{27}$, $13-\mathrm{MeC}_{27}, 9-\mathrm{MeC}_{29}, 11-\mathrm{MeC}_{29}, 13-\mathrm{MeC}_{29}$ and $15-\mathrm{MeC}_{29}$ at $0.3,0.3,0.3,0.15,0.15,0.075$ and $0.075 \mu \mathrm{g}$, respectively $(N=55-60)$. Columns with the same letters indicate no significant differences using Holm's sequential Bonferroni test $(p>0.05)$.

extruded their aedeagus. However, $13-\mathrm{MeC}_{27}, 13-$ $\mathrm{MeC}_{29}, 15-\mathrm{MeC}_{29}$ and $n$-alkanes that were detected in fractions 3 and 4 showed only low activity for eliciting male responses.

Sequentially, we examined male responses to a mixture of these monomethylalkanes at approximately natural amounts. In the female extracts, 9$\mathrm{MeC}_{27}, 11-\mathrm{MeC}_{27}, 13-\mathrm{MeC}_{27}, 9-\mathrm{MeC}_{29}, 11-\mathrm{MeC}_{29}$, $13-\mathrm{MeC}_{29}$ and $15-\mathrm{MeC}_{29}$ were contained at a ratio of approx. $4: 4: 4: 2: 2: 1: 1$ (Table 2). These monomethylalkanes were mixed at $0.3,0.3,0.3,0.15$, $0.15,0.075$ and $0.075 \mu \mathrm{g}$ (total $1.35 \mu \mathrm{g}$ )/FE, respectively, to simulate the natural amounts. When this mixture was applied to a dummy, $66.7 \%$ of the tested males responded to it, though there was a significant difference from the crude extracts $\left(83.3 \%\right.$ of the males responded) by $\chi^{2}$-test $\left(\chi^{2}=4.44, \mathrm{df}=1, p=0.035\right)$ (Fig. 3).

\section{Effect of chemical structures on pheromonal ac- tivity}

The results of the bioassay in Fig. 3 suggest that the pheromonal activity was influenced by a chemical structure; i.e., the length of the carbon backbone and the position of the methyl branch. We synthesized some appropriate monomethylalkanes and evaluated these pheromonal activities (Table $3)$.

A majority of the males $(78.9 \%)$ responded to $11-\mathrm{MeC}_{29}$ and there were no significant differences between 9- $\mathrm{MeC}_{25}, 8-\mathrm{MeC}_{26}, 7-\mathrm{MeC}_{27}, 9-\mathrm{MeC}_{27}$,
Table 3. Relationship between chemical structures and male responses

\begin{tabular}{cc}
\hline Monomethylalkanes $^{\mathrm{a}}$ & Male responses $(\%)^{\mathrm{b}}$ \\
\hline $7-\mathrm{MeC}_{23}$ & $8.5 \mathrm{e}$ \\
$9-\mathrm{MeC}_{23}$ & $5.4 \mathrm{e}$ \\
$5-\mathrm{MeC}_{25}$ & $7.1 \mathrm{e}$ \\
$7-\mathrm{MeC}_{25}$ & $45.8 \mathrm{bc}$ \\
$9-\mathrm{MeC}_{25}$ & $72.9 \mathrm{ab}$ \\
$11-\mathrm{MeC}_{25}$ & $37.3 \mathrm{~cd}$ \\
$8-\mathrm{MeC}_{26}$ & $71.4 \mathrm{ab}$ \\
$7-\mathrm{MeC}_{27}$ & $67.2 \mathrm{abc}$ \\
$9-\mathrm{MeC}_{27}$ & $71.7 \mathrm{ab}$ \\
$11-\mathrm{MeC}_{27}$ & $60.3 \mathrm{abc}$ \\
$13-\mathrm{MeC}_{27}$ & $8.5 \mathrm{e}$ \\
$9-\mathrm{MeC}_{29}$ & $62.1 \mathrm{abc}$ \\
$11-\mathrm{MeC}_{29}$ & $78.9 \mathrm{a}$ \\
$13-\mathrm{MeC}_{29}$ & $6.9 \mathrm{e}$ \\
$15-\mathrm{MeC}_{29}$ & $1.7 \mathrm{e}$ \\
$11-\mathrm{MeC}_{31}$ & $17.2 \mathrm{de}$ \\
\hline
\end{tabular}

${ }^{\text {a }}$ Each compound was applied to a dummy at $2.0 \mu \mathrm{g}$.

${ }^{b}$ Values followed by the same letters indicate no significant differences by Holm's sequential Bonferroni test $(p>0.05)$.

11- $\mathrm{MeC}_{27}, 9-\mathrm{MeC}_{29}$ and $11-\mathrm{MeC}_{29}$ by Holm's sequential Bonferroni test $(p>0.05)$. In contrast, the males exhibited low responses to $7-\mathrm{MeC}_{23}$, 9$\mathrm{MeC}_{23}, 5-\mathrm{MeC}_{25}, 13-\mathrm{MeC}_{27}, 13-\mathrm{MeC}_{29}$ and 15$\mathrm{MeC}_{29}$ (less than $10 \%$ ). About $40 \%$ of the males responded to $7-\mathrm{MeC}_{25}$ and $11-\mathrm{MeC}_{25}$, and there were no significant differences from the responses to high active monomethylalkanes; for example, 7- 
$\mathrm{MeC}_{27}$ and $9-\mathrm{MeC}_{29}$. About $20 \%$ of the males responded to $11-\mathrm{MeC}_{31}$, and there were no significant differences from the responses to low active monomethylalkanes; for example, 7- $\mathrm{MeC}_{23}$ and 9$\mathrm{MeC}_{23}$.

\section{DISCUSSION}

Preliminary observations revealed that male $G$. atrocyanea display typical mating behaviors; i.e., contact a female with the antennae, lick the female with the palpi and extrude aedeagus (Sugeno, unpublished). Because such behaviors have been reported for several cerambycid species in which the female cuticular hydrocarbons functioned as the contact sex pheromone (Fukaya and Honda, 1992; Fukaya et al., 1999; Ginzel et al., 2003a), we speculated that these behaviors in $G$. atrocyanea indicated the existence of a contact sex pheromone. In our experiments, the males predictably attempted to mate with the dummy treated with female elytra extracts (Fig. 1 and Table 1). Furthermore, the fractions separated by Frolisil column chromatography and HPLC also had high pheromonal activity. Upon chemical analysis, the active fractions were found to consist of several $n$-, monomethyl and dimethylalkanes (Fig. 2 and Table 2). These results clearly demonstrated that male G. atrocyanea will exhibit mating behaviors because of chemical compound(s) in the female cuticle rather than visual or tactile cues.

Because methylheptacosanes and methylnonacosanes comprised most of the active fraction, these compounds were synthesized to evaluate the pheromonal activities. The bioassay illustrated in Fig. 3 revealed that $9-\mathrm{MeC}_{27}, 11-\mathrm{MeC}_{27}, 9-\mathrm{MeC}_{29}$ and $11-\mathrm{MeC}_{29}$ were the contact sex pheromones of $G$. atrocyanea. When these monomethylalkanes were applied to the female dummy, about $60-80 \%$ of the males extruded aedeagus towards the dummy. We conducted the evaluations of each alkane at $2.0 \mu \mathrm{g}$ in this bioassay, and this amount, $2.0 \mu \mathrm{g}$, was considered to be notably larger than the amount typically present in the female elytra surface, however, it is clear that these monomethylalkanes individually have the pheromonal capacities for contact sex pheromones. In contrast to the preceding monomethylalkanes, $n$-alkanes, 13$\mathrm{MeC}_{27}, 13-\mathrm{MeC}_{29}$ and $15-\mathrm{MeC}_{29}$ hardly elicited male mating behavior. These compounds were con- sidered to have no (or low) pheromonal activity. When a mixture of seven monomethylalkanes was applied to a female dummy in approximately natural amounts, a number of males $(66.7 \%)$ responded to it. This result suggests that these monomethylalkanes in the female cuticle are the main components of the contact sex pheromone of G. atrocyanea. In spite of the fact that the male response to the mixture was strong enough, the response was significantly lower than that to the crude extracts. Here, in the female extracts, more compounds in addition to the above-mentioned monomethylalkanes were contained. 9- $\mathrm{MeC}_{25}, 11-\mathrm{MeC}_{25}, 10$ $\mathrm{MeC}_{26}$ in fraction 2 (Sugeno, unpublished) and 10$\mathrm{MeC}_{28}$ in fraction 3 showed or inferred having high pheromonal activity (Table 3 and see below) and were detected in the GC-MS analysis. These monomethylalkanes were individually small amounts, but such compounds also additionally work as contact sex pheromones. Dimethylalkanes including the specific structures that active monomethylalkanes have, may also have pheromonal activities. Further, the difference of male responses between the female crude extracts and the hexane fraction $(11.1 \%)$ were larger than the difference between the hexane fraction and the mixture of monomethylalkanes $(7.4 \%)$ (Table 1 and Fig. 3). This suggests that the difference of male responses between the crude extracts and the mixture of monomethylalkanes was largely due to that between the crude extracts and the hexane fraction. The male antennal responses to the female were shown in typical mating. It appears that the crude extracts contain other compounds for releasing male antennal responses. This might explain why the male response to the mixture of monomethylalkanes was lower than that to the crude extracts, although more investigations will be necessary to provide the desired outcome.

$n$-Alkanes $\left(n-\mathrm{C}_{27}, n-\mathrm{C}_{28}, n-\mathrm{C}_{29}\right.$ and $\left.n-\mathrm{C}_{30}\right)$ or low-active monomethylalkanes $\left(13-\mathrm{MeC}_{27}, 13-\right.$ $\mathrm{MeC}_{29}$ and $15-\mathrm{MeC}_{29}$ ) have the same carbon numbers or the same length carbon backbones as active monomethylalkanes (9- $\mathrm{MeC}_{27}, 11-\mathrm{MeC}_{27}, 9-\mathrm{MeC}_{29}$ and $11-\mathrm{MeC}_{29}$ ), but do not branch or differ in the position of the methyl branch. It is clear that the presence of the methyl branch is important to elicit male responses, and it is probable that the branch positions influence the pheromonal activity. Hence, we examined male responses for appropriate 
monomethylalkanes to clarify the relationship between pheromonal activity and chemical structure. The results in Table 3 indicate that the monomethylalkanes with a $25,26,27$ or 29 carbon backbone that are branched at the 7-, 8-, 9- or 11-carbon have high pheromonal activity, while monomethylalkanes with a 23 or 31 carbon backbone or with a branch at the 5-, 13- or 15-carbon have only low activity. It is apparent that both the length of the carbon backbone and the position of the methyl branch greatly influence the pheromonal activity. In the bioassay, only $8-\mathrm{MeC}_{26}$ was tested as the monomethylalkane with an even carbon backbone. This alkane had the same high activity as the odd carbon backbone monomethylalkanes, and it was suggested that there was no difference between odd and even numbers. Probably, monomethylalkanes that have a 25 to 29 carbon backbone and branch at the 7- to 11-carbon possess the capacity to function as the contact sex pheromone of $G$. atrocyanea.

In this paper, we identified the particular cuticular hydrocarbons that function as the contact sex pheromone of $G$. atrocyanea, and this is the first such report in Chrysomelidae. It has been reported that males of the Colorado potato beetle, Leptinotarsa decemlineata, initiate mating behavior in response to female extracts (Jermy and Butt, 1991; Otto, 1997). In Cerambicydae, many identifications of, and much evidence for contact sex pheromones have been found (Allison et al., 2004). In addition, other coleopteran species, for example the Azuki bean weevil, Callosobruchus chinensis (Bruchidae) (Tanaka et al., 1981), the rove beetle, Aleochara curtula (Staphylinidae) (Peschke and Metzler, 1987), and the two-spot ladybird beetle, Adalia bipunctata (Coccinellidae) (Hemptinne et al., 1998), have also been found to utilize cuticular hydrocarbons as contact sex pheromones. For these reasons, it is considered that cuticular hydrocarbons generally play an important role as contact sex pheromones in coleopteran beetles.

\section{REFERENCES}

Allison, J. D., J. H. Borden and S. J. Seybold (2004) A review of the chemical ecology of the Cerambycidae (Coleoptera). Chemoecology 14: 123-150.

Blomquist, G. J., J. A. Tillman-Wall, L. Guo, D. R. Quilici, P. Gu and C. Schal (1996) Hydrocarbon and hydrocarbon derived sex pheromones in insects: biochemistry and endocrine regulation. In Insect Lipids: Chemistry, Biochem- istry, and Biology (D. W. Stanley-Samuelson and D. R. Nelson eds.). University of Nebraska Press, Lincoln, NE, pp. 317-351.

Carlson, D. A., U. R. Bernier and B. D. Sutton (1998) Elution patterns from capillary GC for methyl-branched alkanes. J. Chem. Ecol. 24: 1845-1865.

Fukaya, M., T. Akino, T. Yasuda, S. Tatsuki and S. Wakamura (1999) Mating sequence and evidence for synergistic component in female contact sex pheromone of the White-spotted longicorn beetle, Anoplophora malasiaca (Thomson) (Coleoptera: Cerambycidae). Entomol. Sci. 2: $183-187$.

Fukaya, M., T. Akino, T. Yasuda, S. Wakamura, S. Satoda and S. Senda (2000) Hydrocarbon components in contact sex pheromone of the white-spotted longicorn beetle, Anoplophora malasiaca (Thomson) (Coleoptera: Cerambycidae) and pheromonal activity of synthetic hydrocarbons. Entomol. Sci. 3: 211-218.

Fukaya, M. and H. Honda (1992) Reproductive biology of the yellow-spotted longicorn beetle, Psacothea hilaris (Pascoe) (Coleoptera: Cerambycidae). I. Male mating behaviors and female sex pheromones. Appl. Entomol. Zool. 27: 89-97.

Fukaya, M., T. Yasuda, S. Wakamura and H. Honda (1996) Reproductive biology of the yellow-spotted longicorn beetle, Psacothea hilaris (Pascoe) (Coleoptera: Cerambycidae). III. Identification of contact sex pheromone on female body surface. J. Chem. Ecol. 22: 259-270.

Ginzel, M. D., G. J. Blomquist, J. G. Millar and L. M. Hanks (2003a) Role of contact pheromones in mate recognition in Xylotrechus colonus. J. Chem. Ecol. 29: 533545.

Ginzel, M. D., J. G. Millar and L. M. Hanks (2003b) (Z)-9Pentacosene-contact sex pheromone of the locust borer, Megacyllene robiniae. Chemoecology 13: 135-141.

Hemptinne, J. L., G. Lognay and A. F. G. Dixon (1998) Mate recognition in the two-spot ladybird beetle, Adalia bipunctata: role of chemical and behavioural cues. J. Insect Physiol. 44: 1163-1171.

Jackson, L. L. and G. J. Blomquist (1976) Insect waxes. In Chemistry and Biochemistry of Natural Waxes (P. E. Kolattukudy ed.). Elsevier, New York, pp. 201-233.

Jermy, T. and B. A. Butt (1991) Method for screening female sex pheromone extracts of the Colorado potato beetle. Entomol. Exp. Appl. 59: 75-78.

Kovats, E. (1965) Gas chromatographic characterization of organic substances and the retention index system. $A d v$. Chromatogr. 1: 229-247.

Otto, V. D. (1997) Some properties of the female sex pheromone of the Colorado potato beetle Leptinotarsa decemlineata Say. (Col. Chysomelidae). Anz. Schadlingskde Pflanzenschutz Umweltschutz 70: 30-33.

Peschke, K. and M. Metzler (1987) Cuticular hydrocarbons and female sex pheromones of the rove beetle, Aleochara curtula (Goeze) (Coleoptera: Staphylinidae). Insect Biochem. 17: 167-178.

Pomonis, J. G., C. F. Fatland, D. R. Nelson and R. G. Zaylskie (1978) Insect hydrocarbons: Corroboration of structure by synthesis and mass spectrometry of mono- and di- 
methylalkanes. J. Chem. Ecol. 4: 27-39.

Pomonis, J. G., D. R. Nelson and C. L. Fatland (1980) Insect hydrocarbons 2: Mass spectra of dimethylalkanes and the effect of the number of methylene units between methyl groups on fragmentation. J. Chem. Ecol. 6: 965-972.

Tanaka, N., K. Ohsawa, H. Hiroshi and I. Yamamoto (1981) Copulation release pheromone, Erectin, from the Azuki bean weevil (Callosobruchus chinensis L.). J. Pesticide Sci. 6: 75-82.

Zhang, A., J. E. Oliver, K. Chauhan, B. Zhao, L. Xia and Z. $\mathrm{Xu}$ (2003) Evidence for contact sex recognition pheromone of the Asian longhorned beetle, Anoplophora glabripennis (Coleoptera: Cerambycidae). Naturwissenschaften 90: 410-413. 